08.3;09.1;15.2

\title{
Формирование в ПММА широкополосных центров окраски фемтосекундным лазерным излучением
}

\author{
(c) А.А. Калиничев, О.С. Смирнова, А.В. Поволоцкий \\ Санкт-Петербургский государственный университет, Санкт-Петербург, Россия \\ ฯ E-mail: alexey.povolotskiy@spbu.ru
}

Поступило в Редакцию 28 июня 2019г.

В окончательной редакции 28 июня 2019г.

Принято к публикации 9 июля 2019 г.

В настоящее время при разработке и производстве оптических элементов все чаще используются органические материалы, модифицированные лазерным излучением. Полиметилметакрилат (ПММА) один из широко используемых полимерных материалов в оптике и оптоэлектронике. Основными преимуществами ПММА являются широкое окно прозрачности и простота промышленной обработки. Лазерная модификация ПММА позволяет создавать центры окраски с излучением в широком спектральном диапазоне.

Ключевые слова: лазерная модификация, ПММА, центры окраски.

DOI: 10.21883/PJTF.2019.21.48469.17956

Материалы на основе полиметилметакрилата (ПММА) все чаще используются в производстве оптических устройств. Широкий спектр возможностей лазерной модификации оптических свойств и морфологии ПММА, например изменение показателя преломления, определяет большое разнообразие практического применения данного полимера [1,2]. В настоящее время известны следующие элементы на основе модифицированного лазерным излучением ПММА: нитевидные структуры $[3,4], 3 D$-микрофлюидные устройства $[5,6]$, решетки $[7,8]$, линзы и микролинзы $[9,10]$, пятна субмикронных размеров [11], цветные изображения [12], трехмерные голограммы [13] и центры окраски [14].

Одной из распространенных областей применения материалов на основе ПММА является создание буферных изолирующих защитных слоев для электрооптических устройств [15]. Создание центров окраски позволяет использовать ПММА не только в качестве защитного слоя, но и в качестве оптически активного материала для изменения спектра излучения полупроводниковых лазеров и светодиодов.

Настоящая работа посвящена созданию широкополосных центров окраски в ПММА с помощью сфокусированных фемтосекундных лазерных импульсов. Образцы ПММА синтезировались методом радикальной полимеризации метилметакрилата с использованием перекиси бензоила в качестве инициатора. Для формирования центров окраски в ПММА использовалась вторая гармоника фемтосекундного лазера Coherent Mira Optima 900-D с длиной волны $374 \mathrm{~nm}$, длительностью импульса $150 \mathrm{fs}$, частотой повторения импульсов $10 \mathrm{kHz}$, энергией в импульсе $20 \mathrm{~nJ}$. Лазерное излучение фокусировалось микрообъективом с кратностью увеличения $40 \times$ в фокальную область диаметром около $2 \mu \mathrm{m}$. Возбуждение люминесценции проводилось через этот же микрообъектив непрерывным лазером с длиной волны $360 \mathrm{~nm}$ и мощностью $1 \mu \mathrm{W}$. Спектры люминесценции регистрировались по схеме обратного рассеяния с использованием двойного монохроматора и фотоэлектронного умножителя в режиме счета фотонов.

Абсолютный квантовый выход флуоресценции измерялся на спектрометре Horiba Fluorolog-3. Образцы модифицированного ПММА или свежеприготовленного ПММА помещались в центр интегрирующей сферы, входящей в состав спектрометра. В качестве источника возбуждения использовалась ксеноновая лампа. Квантовый выход определялся по формуле

$$
\Phi=\left(E_{c}-E_{a}\right) /\left(L_{a}-L_{c}\right)
$$

где $E_{c}$ - люминесценция модифицированного образца, $E_{a}$ - люминесценция немодифицированного образца, $L_{c}$ - рэлеевское рассеяние модифицированного образца, $L_{a}$ - рэлеевское рассеяние немодифицированного образца. Спектр поглощения исследуемых образцов измерялся с помощью спектрофотометра Lambda 1050.

Положение фундаментального края оптического поглощения находится в области $380 \mathrm{~nm}$ (рис. 1), что согласуется с известными данными по ПММА [16]. При воздействии фемтосекундными лазерными импульсами на ПММА наблюдается изменение спектров поглощения. Сравнение спектров поглощения модифицированного и немодифицированного ПММА представлено на рис. 1. Видна широкая полоса поглощения в области 400-700 nm, соответствующая центрам окраски, что хорошо согласуется с данными работы [14] по формированию центров окраски фемтосекундным лазерным излучением в ПММА.

Кроме того, лазерная модификация ПММА влияет на люминесцентные свойства полимера. Так, с помощью фемтосекундных лазерных импульсов в ПММА сформированы широкополосные центры окраски. Модифицированный ПММА при длине волны возбуждающего излу- 


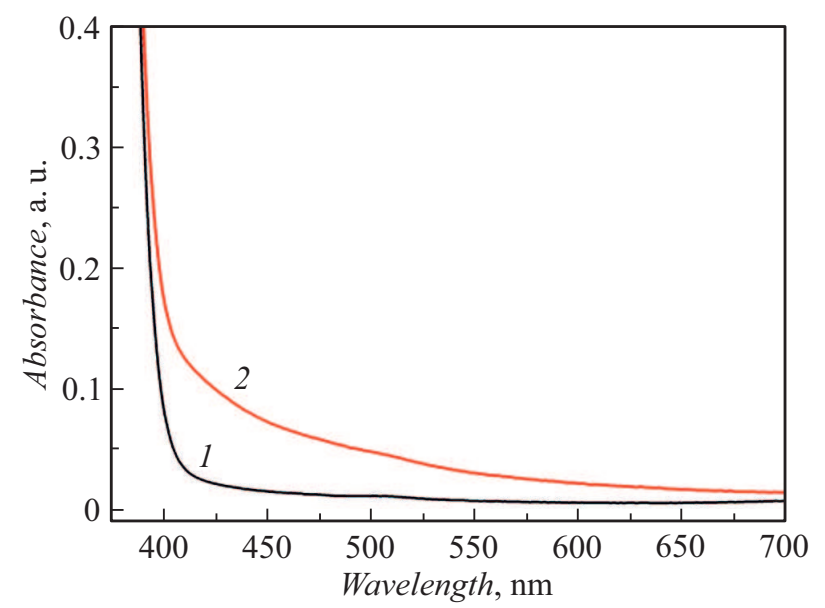

Рис. 1. Спектры поглощения ПММА (1) и модифицированного ПММА (2).
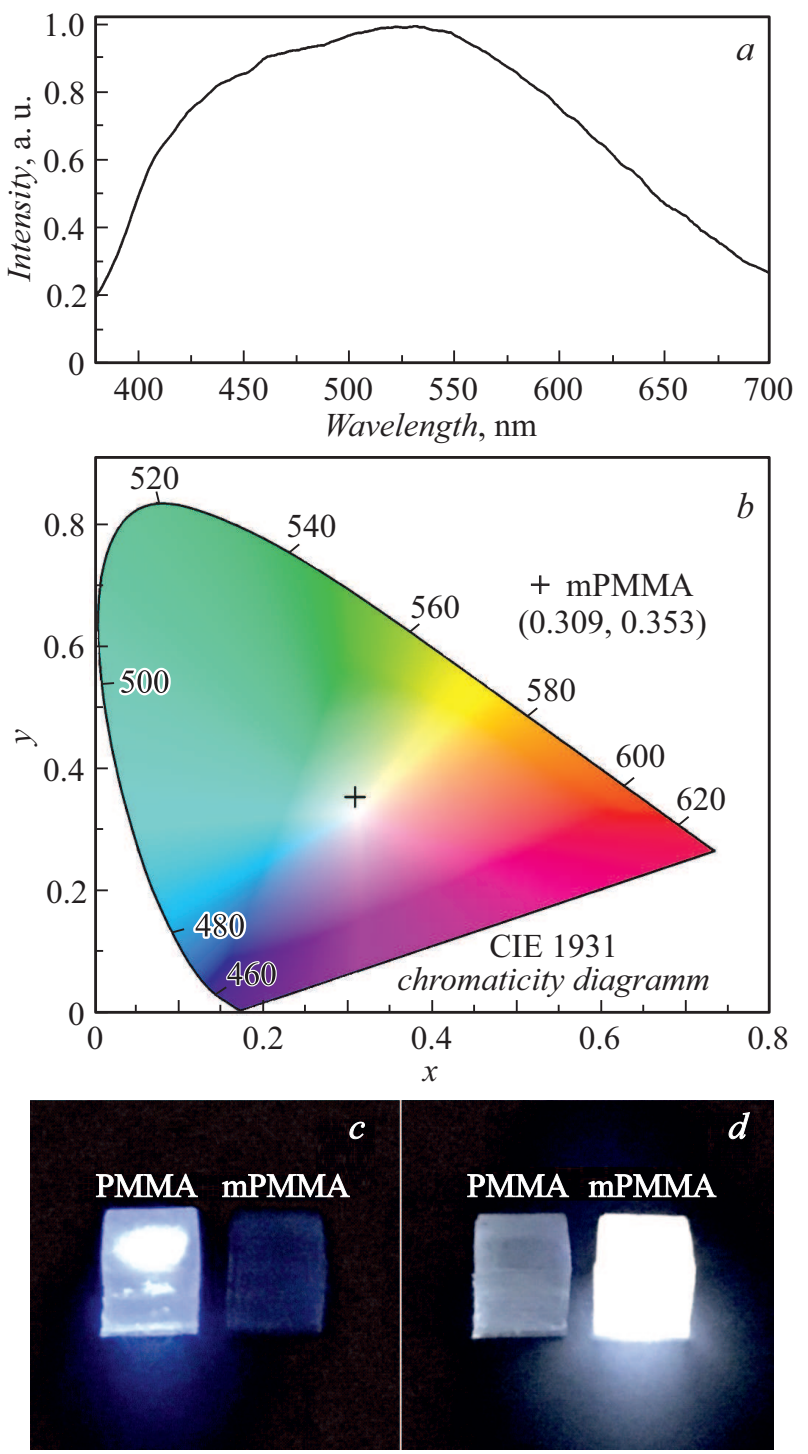

Рис. 2. $a-$ спектр фотолюминесценции модифицированного ПММА (mРММА), $b$ - диаграмма цветности модифицированного ПММА при длине волны возбуждающего излучения $360 \mathrm{~nm}, c-$ УФ-возбуждение образца ПММА, $d-$ УФ-возбуждение образца модифицированного ПММА.

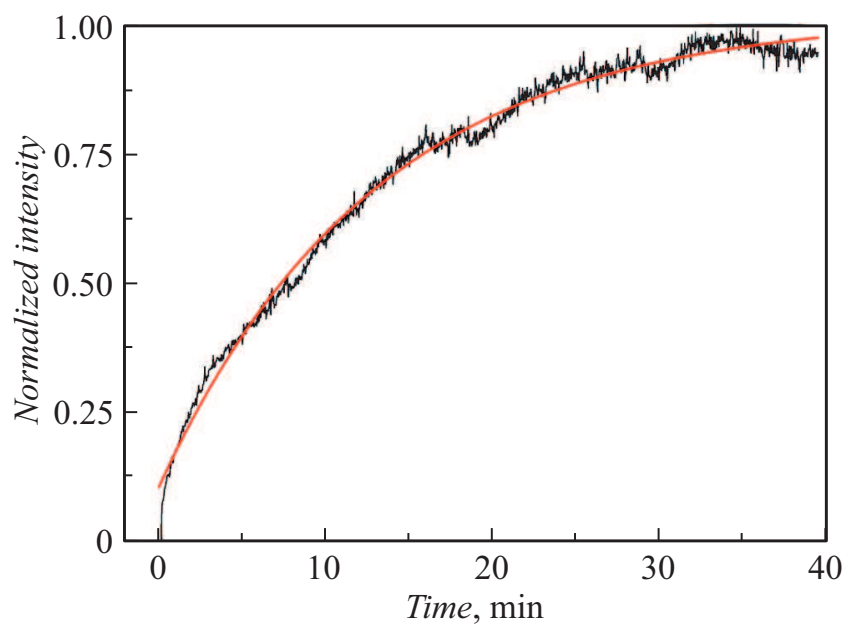

Рис. 3. Кинетическая кривая формирования центров окраски в ПММА.

чения $360 \mathrm{~nm}$ люминесцирует в широком спектральном диапазоне (рис. 2,a), квантовый выход люминесценции при этом достигает $38 \%$. На рис. 2, $b$ представлена диаграмма цветности люминесценции. Очевидно, сформированные в ПММА центры окраски обладают спектром люминесценции, близким к спектру белого света. Фотографии люминесцирующих образцов немодифицированного (рис. 2,c) и модифицированного (рис. 2,d) ПММА при возбуждении $360 \mathrm{~nm}$ демонстрируют появление люминесценции центров окраски. Ультрафиолетовый луч возбуждения поочередно направлен сначала на полиметилметакрилат, затем на модифицированный полиметилметакрилат.

Кинетика формирования центров окраски исследовалась на той же установке, на которой производилась лазерная модификация ПММА. В этом случае импульсный фемтосекундный лазер использовался для локальной модификации образца, а непрерывный с мощностью около $1 \mathrm{~mW}$ - для возбуждения люминесценции центров окраски. Регистрация интенсивности излучения осуществлялась при помощи фотоэлектронного умножителя в режиме счета фотонов. Кинетическая кривая лазерно-индуцированного формирования центров окраски представлена на рис. 3. Интенсивность люминесценции монотонно увеличивается, демонстрируя экспоненциальный рост количества центров окраски. Стабилизация интенсивности люминесценции свидетельствует об отсутствии оптического обесцвечивания центров окраски, что делает модифицированный ПММА перспективным люминофором.

Таким образом, лазерно-индуцированная модификация ПММА приводит к появлению широкополосных центров окраски с высоким квантовым выходом до $38 \%$. Если учесть также низкую стоимость, простоту формовки и доступность ПММА, лазерная модификация может быть использована для создания конкурентоспособных люминофоров на его основе. 


\section{Благодарности}

Исследования проводились с использованием оборудования ресурсного центра „Оптические и лазерные методы исследования вещества“ Научного парка СПбГУ.

\section{Конфликт интересов}

Авторы заявляют, что у них нет конфликта интересов.

\section{Список литературы}

[1] Baum A., Scully P.J., Perrie W., Jones D., Issac R., Jaroszynski D.A. // Opt. Lett. 2008. V. 33. P. 651-653.

[2] Baum A., Scully P.J., Basanta M., Paul Thomas C.L., Fielden P.R., Goddard N.J., Perrie W., Chalker P.R. // Opt. Lett. 2007. V. 32. P. 190-192.

[3] Matushiro Y. // J. Laser Micro/Nanoeng. 2016. V. 11. P. 5965.

[4] Watanabe W. // Laser Phys. 2009. V. 19. P. 342-345.

[5] Volpe A., Di Niso F., Gaudiuso C., De Rosa A., Martínez Vázquez R., Ancona A., Lugará P.M., Osellame R. // Opt. Express. 2015. V. 23. P. 4114-4124.

[6] Roth G.-L., Esen C., Hellmann R. // Opt. Express. 2017. V. 25. P. $18442-18450$.

[7] Watanabe W. // J. Laser Micro/Nanoeng. 2017. V. 12. P. 102 106.

[8] Kelb C., Pätzold W.M., Morgner U., Rahlves M., Reithmeier E., Roth B. // Opt. Mater. Express. 2016. V. 6. P. 3202-3209.

[9] Heberle J., Häfner T., Schmidt M. // J. Laser Appl. 2016. V. 28. P. 022604.

[10] Ou Y., Yang Q., Chen F., Deng Z., Du G., Wang J., Bian H., Yong J., Hou X. // IEEE Photon. Technol. Lett. 2015. V. 27. P. 2253-2256.

[11] Caballero-Lucas F., Florian C., Fernández-Pradas J.M., Morenza J.L., Serra P. // Appl. Surf. Sci. 2016. V. 374. P. 353358.

[12] Sohn I.-B., Choi H.-K., Yoo D., Noh Y.-C., Sung J.-H., Lee S.-K., Ahsan M.S., Lee H. // Opt. Mater. 2017. V. 69. P. 295-302.

[13] Sohn I.-B., Choi H.-K., Yoo D., Noh Y.-C., Noh J., Ahsan M.S. // Appl. Surf. Sci. 2018. V. 427. P. 396-400.

[14] Samad R.E., Courrol L.C., Lugão A.B., Freitas A.Z., Vieira N.D. // Rad. Phys. Chem. 2010. V. 79. P. 355-357.

[15] Yamaguchi T., Hagino H. // Opt. Lasers Eng. 2017. V. 88. P. 13-19.

[16] Pflug T., Olbrich M., Roesch R., Schubert U.S., Hoppe H., Horn A. // Opt. Lasers Eng. 2018. V. 111. P. 130-134. 